\title{
SPECTROPHOTOMETRIC DETERMINATION OF SERTRALINE IN PURE AND BLOOD SAMPLE
}

\author{
MUHAMMAD JAHANGIR, FAISAL RIAZ, ASIF HANIF CHAUDHRY* \\ Department of Chemistry, GC University, Lahore. \\ Department of Chemistry, GC University, Lahore. \\ Department of Chemistry, University of Wah, Wah Cantt \\ (Received: March 16, 2010 - Accepted: March 14, 2011)
}

\begin{abstract}
A simple and sensitive spectrophotomteric method has been developed for the determination of Sertraline in pharmaceutical and blood sample. The current method is depend upon the reaction between the sertraline and chloranilic acid in slightly alkaline medium, giving a purple colour complex having maximum absorbance at $527.5 \mathrm{~nm}$. The reaction is selective for sertraline with $0.01 \mathrm{mg} / \mathrm{mL}$. The colour reaction obeys Beer's law from $0.1 \mathrm{mg}$ to $5 \mathrm{mg} / \mathrm{mL}$ of sertraline and relative standard deviation is $0.19 \%$. The quantitative estimation of sertraline in blood sample is also studied.
\end{abstract}

Key Words: Spectrophotometric, Sertraline, chloranilic acid, Beer's law, quantitative estimation.

\section{INTRODUCTION}

Sertraline Hydrochloride is a Selective Serotonin Reuptake Inhibitor (SSRI) and is a tricyclic compound with antidepressant activity ${ }^{1}$. The antidepressant effect of sertraline is presumed to be linked to its ability to inhibit the neuronal reuptake of serotonin ${ }^{2}$. It has only very weak effects on norepinephrine and dopamine neuronal reuptake. At clinical doses, sertraline blocks the uptake of serotonin into human platelets ${ }^{3}$. Like most clinically effective antidepressants, sertraline down regulates brain norepinephrine and serotonin receptors in animals ${ }^{4}$. In receptor binding studies, sertraline has not a significant affinity for adrenergic (alpha(1),alpha(2) and beta), cholinergic, GABA, dopaminergic, histaminergic, serotonergic(5-HTIA,5-HTIB,5-HT2) or benzodiazepine binding sites ${ }^{5}$. In placebo- controlled studies in normal volunteers, sertraline did not cause sedation and did not interfere with psychomotor performance ${ }^{6}$.

Various analytical techniques have been developed for the determination of Sertraline $\mathrm{HCl}$. In the UV-VIS spectrophotometric determinations, colour was obtained by the reaction of sertraline $\mathrm{HCl}$ with either $\mathrm{p}$ acceptors chloranil and 2,3-dichloro-5,6-dicyanoquinone (DDQ) or s acceptor iodine ${ }^{7}$. In the qualitative analysis of some antidepressants by first derivative spectrophotometry and HPLC, antidepressant (sertraline $\mathrm{HCl}$ ) is determined (analysed). In the first derivative spectrophotometry, sertraline hydrochloride by measurement of its first derivative signals at $271.6-275.5 \mathrm{~nm}$ (peak-to-peak amplitude) and in the HPLC method, the UV detection were carried out at $270.0 \mathrm{~nm}^{8}$.

Structure of Sertraline and Chloranilic acid

Sertraline<smiles>CN[C@H]1CC[C@@H](c2ccc(Cl)c(Cl)c2)c2ccccc21</smiles>

Chloranilic acid Experimental

\section{Apparatus}

A UV-VIS spectrophotometer (Techcomp-UV2300) was used to measure the absorbance. A pH meter (Cyber Scan) and graduated pipettes were employed.

\section{Reagent:}

All reagents were of analytical grade and doubly distilled water was used. Sertraline standard solution $(\mathrm{w} / \mathrm{v}) 0.5 \mathrm{mg} / \mathrm{mL}$ was prepared by dissolving $50 \mathrm{mg}$ sertraline $\mathrm{HCl}$ in $10.0 \mathrm{~mL}$ distilled water. The solution was made alkaline ( $\mathrm{pH} \sim 11)$ by slowly adding $10 \% \mathrm{NaOH}$ solution (checked with $\mathrm{pH}$ paper). Transferred it to a separating funnel and added $20.0 \mathrm{~mL}$ of chloroform. Shaked well and allowed to stand and separated lower portion of chloroform (leaving a very small portion behind). Repeated this step thrice and passed the extract through a funnel embedded with anhydrous $\mathrm{Na}_{2} \mathrm{SO}_{4}$. The solution was made up to $100 \mathrm{~mL}$ with chloroform ${ }^{9}$

$0.005 \%(\mathrm{w} / \mathrm{v})$ chloranilic acid was prepared by dissolving $0.05 \mathrm{~g}$ of it in $25 \mathrm{~mL}$ methanol and the volume was made up to $100 \mathrm{~mL}$ with methanol.

$1 \mathrm{M}(\mathrm{w} / \mathrm{v})$ sodium hydroxide (E. Merck) was prepared in distilled water.

\section{General Procedure}

To an aliquot of sertraline, added $0.2 \mathrm{~mL}$ of chloranilic acid and measured the absorbance of the resulting purple color at $527.5 \mathrm{~nm}$. After this, performed different effects including concentration of reagents, $\mathrm{pH}$, time, temperature, complex stability and finally a calibration curve was drawn (Fig-I).

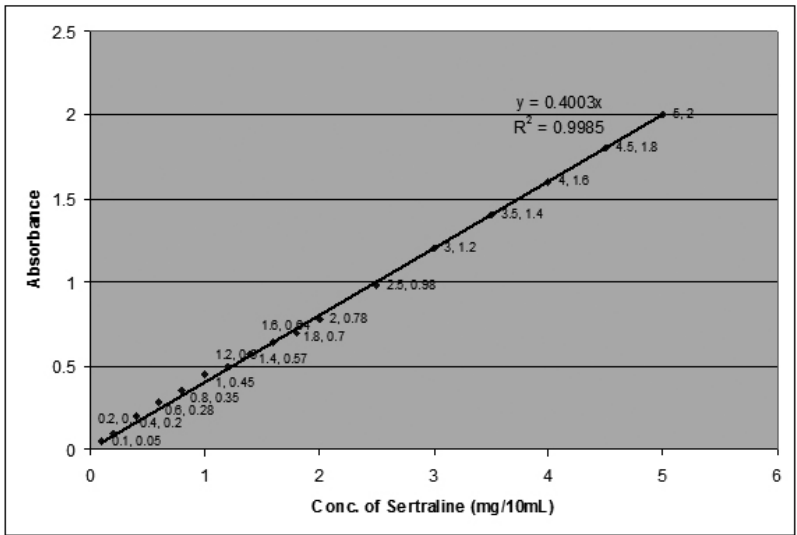

Fig-I Calibration Curve of Sertraline $(0.1-5 \mathrm{mg} / 10 \mathrm{~mL})$ 
Conditions: $0.005 \%$ chloranilic acid, Temperature $32^{\circ} \mathrm{C}, \mathrm{pH}=11.15$, $\lambda_{\text {max }}=527.5 \mathrm{~nm}$

\section{RESULTS AND DISCUSSION}

\section{Absorption Spectrum of Colored Complex}

Sertraline reacts with chloranilic acid without any heating give purple color complex, the absorption maxima of which under optimum condition, is at $527.5 \mathrm{~nm}$ (Fig-II).

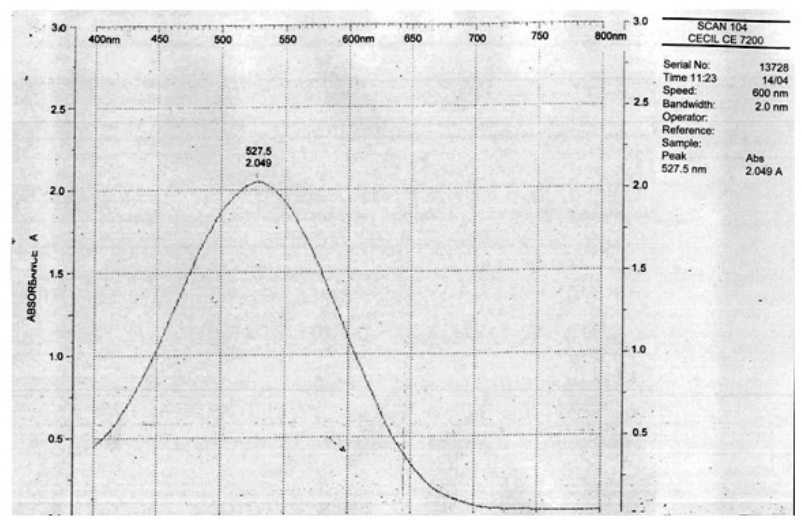

Fig-II Absorption spectra of Sertraline-Chloranilic acid complex

Conditions: Sertraline $0.5 \mathrm{mg} / \mathrm{mL}$, Room Temperature, $\lambda_{\max }$ found $=$ $527.5 \mathrm{~nm}$

\section{Effect of Color Producing Reagent}

Chloranilic acid was used as a color producing reagent. It was found that the complex was stable and with the increase the concentration of chloranilic acid $(\mathrm{mL})$, increase in the absorbance observed, thus a linear relationship observed as in Fig-III.

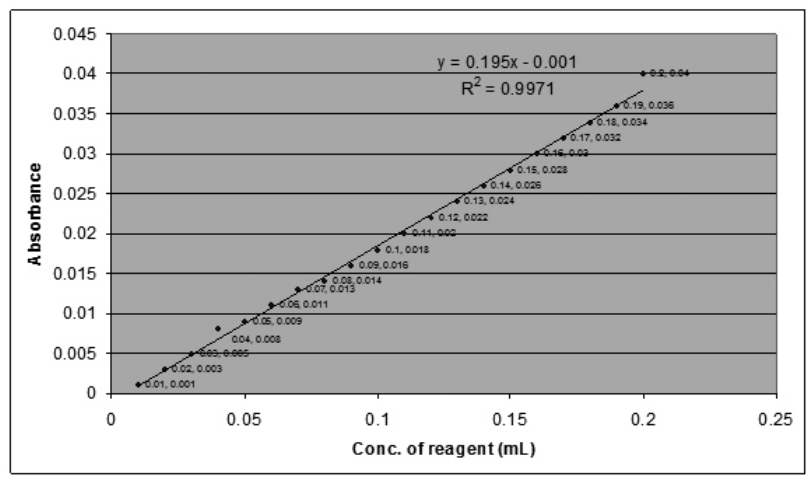

Fig. III Effect of concentration of reagent (chloranilic acid)

Conditions: Sertraline $=0.5 \mathrm{mg} / \mathrm{mL}$, Room Temperature, $\mathrm{pH} \sim 10, \lambda_{\max }$ $=527.5 \mathrm{~nm}$

\section{Effect of pH}

When Sertraline was mixed with chloranilic acid without the addition of $\mathrm{NaOH}$, the $\mathrm{pH}$ was 5.5 and the color was purple. Though for the complete reaction $\mathrm{pH}$ should be greater than 7 and complex would be stable. However at $\mathrm{pH}=11.15$ give the maximum intensity as shown in the Fig-IV.

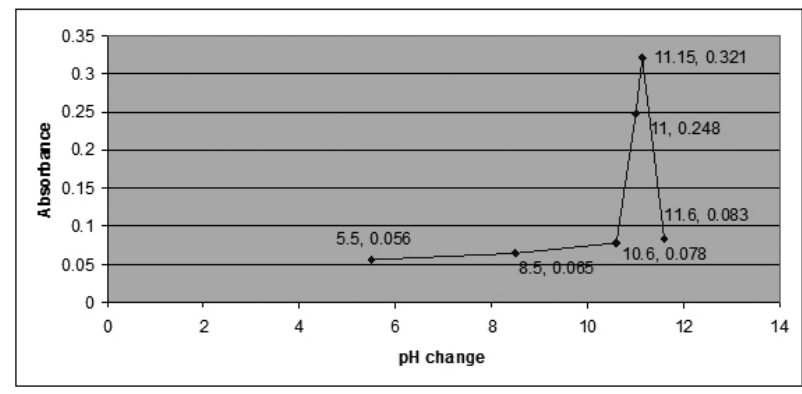

Fig. IV: Effect of $\mathrm{pH}$ on formation of Color complex

Conditions: Sertraline $=0.5 \mathrm{mg} / \mathrm{mL}, 0.005 \%$ chloranilic acid, $\left(\lambda_{\max }=\right.$ $527.5 \mathrm{~nm})$

\section{Effect of Temperature}

The effect of temperature is shown in Fig.V. The colour develops at room temperature. As the temperature increases the complex starts dissociating, due to which the colour intensity decreases. It was found that heating at $30^{\circ} \mathrm{C}$ gave maximum colour, however above and below this temperature the colour intensity decreased and the colour was unstable.

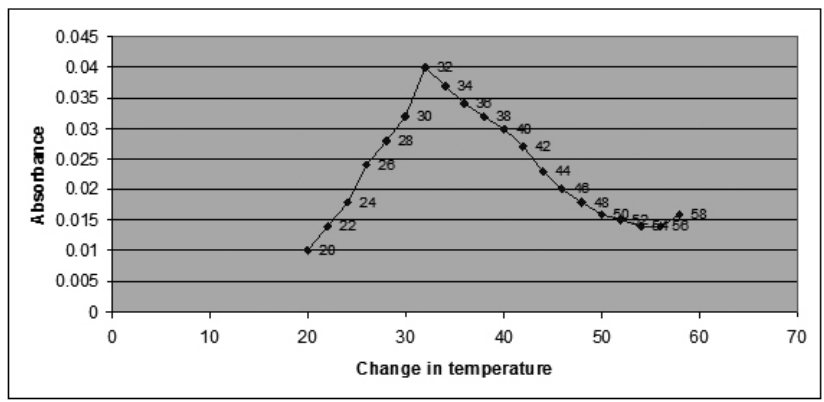

Fig. V Effect of Temperature on stability of color complex

Conditions: Sertraline $=0.5 \mathrm{mg} / \mathrm{mL}, 0.005 \%$ chloranilic acid, $\lambda_{\max }=$ $527.5 \mathrm{~nm}$

\section{Effect of Heating Time}

The color develops at room temperature, but as the time increases the color intensity decreases. It was found that heating for $20 \mathrm{~min}$ gave maximum color above and below which, color was unstable (Fig-VI).

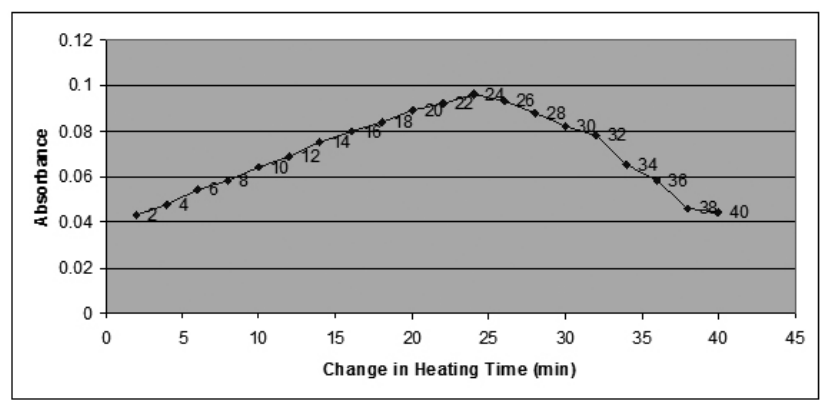

Fig. VI: Effect of Heating Time on formation of color complex

Conditions: Sertraline $=0.5 \mathrm{mg} / \mathrm{mL}, 0.005 \%$ chloranilic acid, Temp. $=$ $32^{\circ} \mathrm{C}, \lambda_{\max }=527.5 \mathrm{~nm}$

\section{Effect of time on stability of colour}

To study the stability of the color, $5.0 \mathrm{~mL}$ of Sertraline $(0.5 \mathrm{mg} / \mathrm{mL})$ was mixed with $0.2 \mathrm{~mL}$ of Chloranilic Acid $(0.005 \%)$ and heated at $30^{\circ} \mathrm{C}$. Absorbance was noted after every 5 minutes. A graph was plotted between the time and absorbance. These results are plotted in Fig. VII which shows that there is no effect of time on stability of color. 


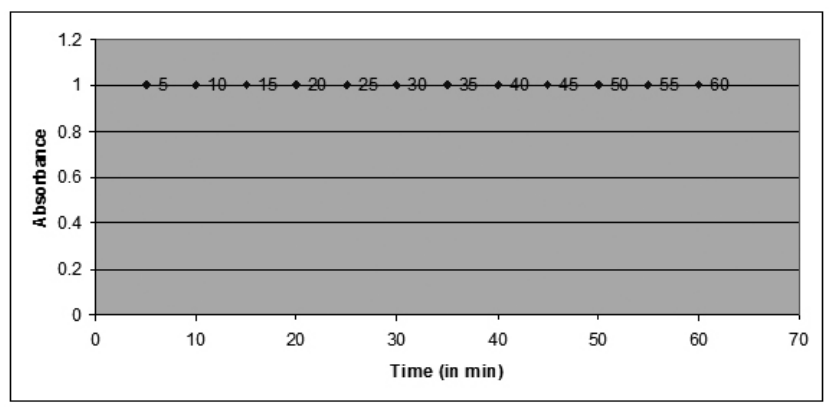

Fig.VII: Effect of time of stability of color

Conditions: Sertraline $=0.5 \mathrm{mg} / \mathrm{mL}, 0.005 \%$ chloranilic acid, Room Temp., $\lambda_{\max }=527.5 \mathrm{~nm}$

\section{Validity on Blood Sample:}

Took blood sample in anticoagulant tube and centrifuge it at $4000 \mathrm{rpm}$ for 5 minutes. Serum was separated from the blood and divided in to eight portions (vials). Then added different concentrations of drug (i.e. $0.5 \mathrm{~mL}, 1.0 \mathrm{~mL}$, $1.5 \mathrm{~mL}, 2.0 \mathrm{~mL}, 2.5 \mathrm{~mL}, 3.0 \mathrm{~mL}, 3.5 \mathrm{~mL}, 4.0 \mathrm{~mL}$ ) in the centrifuge tubes and $3 \mathrm{~mL}$ acetonitrile was also added in each of the tube. Again centrifuge them at 5000 rpm for the removal of proteins. After separation of serum, added $0.2 \mathrm{~mL}$ of reagent (chloranilic acid) in each of the eight tubes (or vials) and measured the absorbance at $527.5 \mathrm{~nm}$. The results showed that the method may be applicable on biological sample and an excellent method for determination of sertraline from $1.5 \mathrm{mg} / \mathrm{mL}$ to $2.5 \mathrm{mg} / \mathrm{mL}$. Results expressed in Fig VIII and IX.

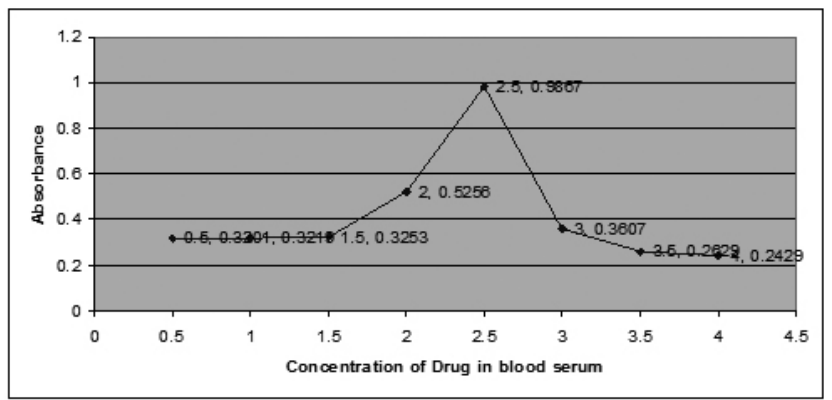

Fig. VIII: Concentration of Sertraline in blood samples

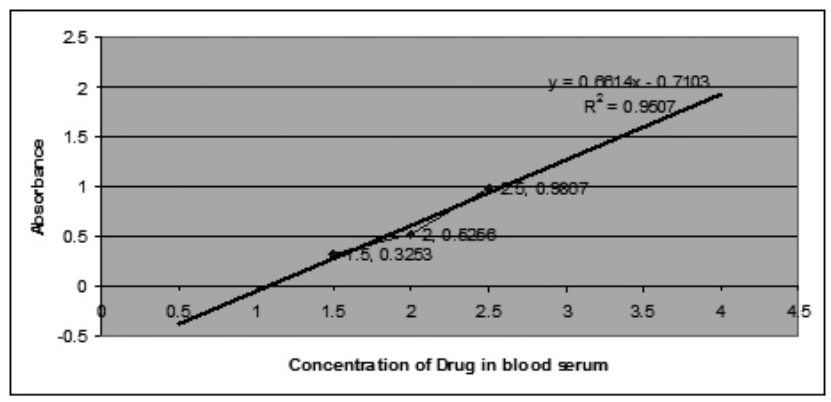

Fig. IX: Concentration of Sertraline in blood sample

\section{Sensitivity}

The recovery results for the determination of Sertraline in solutions are shown in Table I, which shows the sensitivity and reproducibility of the method. It is also reasonable precise and accurate, as the amount taken from identical samples is known and the amount found does not exceed a relative standard deviation of $0.19 \%$ for six values. The optimization has been done at lower analyte concentration.

\begin{tabular}{|c|c|c|}
\hline Table 1: Determination of Sertraline & from Pure & So. \\
\hline $\begin{array}{c}\text { Sertraline HCl } \\
\text { taken }(\mathbf{m g} / \mathbf{m L})\end{array}$ & $\begin{array}{c}\text { Sertraline HCl } \\
\text { recovered }(\mathbf{m g} / \mathbf{m L})\end{array}$ & RSD (\%) \\
\hline 0.05 & 0.0502 & 0.18 \\
\hline 0.1 & 0.0998 & 0.11 \\
\hline 0.15 & 0.1493 & 0.26 \\
\hline 0.2 & 0.2006 & 0.09 \\
\hline 2 & 2.003 & 0.08 \\
\hline 3 & 3.007 & 0.04 \\
\hline 4 & 3.997 & 0.08 \\
\hline 5 & 5.008 & 0.06 \\
\hline
\end{tabular}

The overall findings are summarized in $\underline{\text { Table II }}$

Table II : Determination of Sertraline from Pure Solution.

\begin{tabular}{|c|c|}
\hline Parameter & Value \\
\hline$\lambda \max (\mathrm{nm})$ & $527.5 \mathrm{~nm}$ \\
\hline Beer's law limit $(\mathrm{mg} / \mathrm{ml})$ & $0.01-5.0$ \\
\hline Limit of detection $(\mathrm{mg} / \mathrm{ml})$ & 0.01 \\
\hline Optimum photometric range & $0.01-5.0$ \\
\hline Relative standard deviation (RSD) (\%) & 0.19 \\
\hline
\end{tabular}

\section{BIBLIOGRAPHY}

1. W. M Welch, Discovery and preclinical development of the serotonin reuptake inhibitor sertraline, Advances in Medicinal Chemistry.3, 113148, (1995).

2. D. Healy, The Antidepressant Era. Cambridge, Massachusetts: Harvard University Press.168, (1999).

3. J. Couzin, The Brains Behind Blockbusters. Science. 309, 728, (2005).

4. R. Sarges, JR Tretter, SS Tenen, A. Weissman, "5, 8-Disubstituted 1-Aminotetralins. A Class of Compounds with a Novel Profile of Central Nervous System Activity. Journal of Medicinal Chemistry, 16, 1003, (1973).

5. L. F Fabre, F. S Abuzzahab, M Amin, J. L Claghorn. J Mendels. W. M Petrie. S. Dubé, J. G Small, Sertraline safety and efficacy in major depression: a double-blind fixed-dose comparison with placebo. Biol. Psychiatry. 38, 592, (1995).

6. I. B Lories, E. K Naglaa, K. S Jihan, S. Mohamed, Spectrophotometric determination of fluoxetine and sertraline using chloranil, 2, 3 dichloro-5, 6 dicyano benzoquinone and iodine. Journal of Pharmaceutical and Biomedical Analysis. 21, 133, (1999).

8. Erk Nevin, Rapid and simple methods for quantitative analysis of some antidepressant in pharmaceutical formulations by using first derivative spectrophotometry and HPLC. Il Farmaco. 58, 1209, (2003).

9. A. D. Ibrahim, Spectrophotometric analysis of selective serotonin reuptake inhibitors based on formation of charge-transfer complexes with tetracyanoquinodimethane and chloranilic acidJournal of AOAC International. 88: 1, (2005). 